\title{
Mário Augusto Medeiros da Silva - A descoberta do insólito: literatura negra e literatura periférica no Brasil (1960-2000)
}

Rio de Janeiro: Aeroplano, 2013

\section{Lucas Amaral de Oliveira ${ }^{1}$}

Para além das efemérides geradas pela Copa do Mundo e pelas eleições no Brasil, observou-se, em 2014, uma miríade de solenidades pelo país afora. A memória revelou-se, para o bem ou para o mal, bastião maior de eventos, debates, encontros e atos culturais e políticos. Em especial, "comemorou-se" o centenário de Carolina Maria de Jesus, os cinquenta anos de publicação da obra $A$ integração do negro na sociedade de classes (2008 [1964]), de Florestan Fernandes, e, sobretudo, o cinquentenário do golpe civil-militar no Brasil - com a entrega, no fim desse ano, do relatório final da Comissão Nacional da Verdade, em cerimônia oficial no Palácio do Planalto, à presidenta Dilma Rousseff. Em pesquisa de vigor invejável, o sociólogo Mário Augusto Medeiros da Silva, na obra A descoberta do insólito: literatura negra e literatura periférica no Brasil (1960-2000), explora habilmente questões que tangenciam essas três datas trazidas à memória.

Nesse sentido, Walter Benjamin (1996) parece apropriado, hoje, para ponderar o entusiasmo às vezes impensado em torno das datas solenes. Para o filósofo, "rememorar" não é sinônimo de "comemorar". A comemoração estaria calcada numa celebração piedosa, meramente contemplativa - comum aos cerimoniais públicos. A rememoração, pelo contrário, seria um zelo que agiria sobre o presente, equacionando-o de forma reflexiva. Jeanne Marie Gagnebin (2006), em raciocínio consoante ao de Benjamin, alerta que é um imperativo lembrar o passado; porém, não só "lembrar por lembrar", numa espécie de culto estanque ao que passou: a reivindicação do não esquecimento não é apelo a comemorações oficiais; é, isso sim, exigência para um exame mais esclarecedor do passado, capaz de produzir instrumentos de análise para a melhor compreensão do presente. E, visto que a memória funciona como ascese da história, o pesquisador, tanto quanto possível, deve abrir-se aos buracos, às lacunas, ao esquecido e recalcado, para

\footnotetext{
${ }^{1}$ Doutorando no programa de pós-graduação em sociologia da Universidade de São Paulo (USP), SP, Brasil. Bolsista FAPESP. E-mail: lucas_amaral_oliveira@hotmail.com
} 
exprimir "aquilo que ainda não teve direito nem à lembrança nem às palavras" (Gagnebin, 2006, p. 55).

A pesquisa de Mário Augusto, nessa medida, escova a história a contrapelo, pois, antes de apontar para uma imagem intocável e estática do passado, enquanto monumento simbólico, vazio e que nada instrui sobre o porvir, busca construir uma experiência com ele - no sentido benjaminiano do termo -, tendo como alicerce artefatos materiais e simbólicos diversos: documentos, narrativas, memórias, testemunhos. Prova disso é o provocante início do livro, que lança uma questão chave que percorrerá as entrelinhas de toda a sua pesquisa sociológica - e arqueológica, dada a ênfase na apreciação de múltiplos vestígios históricos. O que explica o surgimento, muitas vezes em condições e situações bastante adversas, de um criador literário?

[O que explica a concepção de um grande livro,] longe de escrivaninhas, dos círculos cultos ou cultuados e do sossego das bibliotecas bem servidas? Primo Levi nos campos de concentração; Jean Genet nas cadeias francesas; Luiz Alberto Mendes no Presídio Carandiru; Pepetela e Luandino Vieira no calor das guerrilhas de libertação angolanas; Carolina Maria de Jesus na favela do Canindé; João Antônio em Vila Anastácio etc.; Graciliano Ramos na prisão e no porão de navios; Lima Barreto no cemitério dos vivos; De Sade nas masmorras. Os exemplos são vários e contínuos na história literária (p. 24, grifos do original).

De fato, são muitos, e o autor faz emergir alguns deles em sua obra às vezes, esquecidos pela crítica ou deixados de lado pela história.

Prêmio para Jovens Cientistas do Centro de Estudos Sociais da Universidade de Coimbra, em 2013, e Menção Honrosa da Associação Nacional de Pós-Graduação em Ciências Sociais, em 2012, o pesquisador da Unicamp debruça-se sobre intelectuais e ativistas brasileiros que se autodenominaram negros ou periféricos, a fim de explorar, a partir de fontes primárias e secundárias - entrevistas, observação direta, participação em eventos, exame de documentos, gravações, leitura de acervos, fotos -, as relações de alguns escritores com coletivos culturais, privilegiando as dificuldades de publicação, as questões identitárias inerentes às propostas estéticas, os processos criativos e as proximidades e distâncias entre as concepções de literatura negra e, mais recentemente, literatura periférica no Brasil. 
A partir disso, o livro discute aspectos das trajetórias e obras de alguns autores e coletivos de escritores negros e periféricos na segunda metade do século XX, a saber: Carolina Maria de Jesus (1914-1977); coletivo Quilombhoje, com a série Cadernos Negros (1978-), cuja origem está em encontros de intelectuais como Oswaldo de Camargo e Cuti; Paulo Lins (1958-); e Ferréz (1975-). Seu projeto visa compreender os alcances e limites das ideias de literatura negra e periférica, o que as aproxima e as separa, bem como as relações dessas produções estéticas com os ativismos políticos de ambos os movimentos, com os quais elas dialogam ou, por vezes, atritam-se. Afinal, "quem não se atrela aos elementos formais daquelas ideias, embora pertença ao mesmo grupo social de origem, que relações mantêm com a ética criativa e política?", provoca Mário, ainda na introdução (p. 25).

Não se deve deixar de reconhecer, nesse contexto, o papel pioneiro que desempenhou o ativismo de alguns escritores negros, como Solano Trindade, Cuti, Eduardo de Oliveira, Oswaldo de Camargo e Miriam Alves, na segunda metade do século XX, mormente na cidade de São Paulo, em torno de estratégias coletivas de ação política e cultural. Com esse alerta, a pesquisa aprofunda-se numa leitura da história, por vezes conflituosa, das associações negras e seus vários projetos e parcerias em consonância com intelectuais como Florestan Fernandes, Roger Bastide e Clóvis Moura. Propondo um exercício analítico interessante, o pesquisador verifica a forma a partir da qual determinados escritores negros conseguiram angariar espaço dentro do complexo sistema literário brasileiro, nas décadas de 1960 e 1970, buscando contrapontos e aproximações com o papel de intelectuais das ciências sociais que, pelo menos até o fatídico golpe de 1964, dedicaram-se a estudar associações e produções culturais negras.

A obra possui cerca de setecentas páginas e está dividida em três partes, dentro das quais se encontram dez capítulos de fôlego. A primeira parte, que contém dois capítulos, investe, num primeiro momento, no exame crítico de trabalhos que debateram a formação e a história da literatura negra - focando na importância da imprensa e do ativismo negro -, bem como a luta desse movimento contra alguns estigmas sociais que, de muitas maneiras, perpassavam a produção literária desse grupo socialmente negativizado. Num segundo momento, o autor analisa a emergência de uma literatura periférica atrelada a movimentos culturais recentes (como os saraus poéticos) que tomaram de assalto a cena pública 
paulistana, sugerindo algumas "conexões de sentidos" entre aspectos idiossincráticos da história da literatura negra e a recente literatura marginal-periférica. A hipótese é a de que há uma afinidade temática e até mesmo um parentesco cultural e político da literatura negra com a literatura periférica. Assim, lançando mão de uma chave interpretativa tão variada quanto sofisticada, a tese problematiza que a investida na noção de "marginalidade" desses novos autores periféricos atuais está, talvez, mais relacionada à condição histórica de subalternidade da ideia de literatura negra do que propriamente com a chamada Geração do Mimeógrafo, da década de 1970 - ligação esta trabalhada pela antropóloga Érica Peçanha do Nascimento (2009), interlocutora importante com o estudo de Mário Augusto.

A segunda parte do livro é fruto de uma reviravolta instigante, por intermédio da qual o sociólogo manifesta um domínio exemplar de teoria social brasileira. Nesse momento, é matizado o percurso que levou alguns cientistas sociais de estirpe a dedicar suas pesquisas à história e aos desdobramentos do ativismo negro e, eventualmente, à própria questão da estética literária negra. Mas o ponto forte dessa parte manifesta-se quando, em certa altura, a problemática é invertida: afinal, qual o interesse do protagonismo negro nos estudos acadêmicos orientados por sociólogos da Universidade de São Paulo? “Qual seria o ânimo que levava associações e grupos negros a colaborar com aquelas pesquisas, fornecendo-lhes dados, entrevistas, documentações, procurando dialogar consigo etc.?" (p. 251). Essas questões estão presentes no terceiro e no quarto capítulos, ao que se segue uma hipótese lançada à guisa de resposta: o encontro entre o ativismo político e literário negro com a sociologia paulista, bem como os anseios de ambos os lados, não se fez sem arranjos diversos, tensões e choques.

Após o golpe de 1964, um longo intervalo se instaurou no associativismo negro, o que fez com que tanto a produção estética quanto o ativismo se mantivessem em surdina, para seu ressurgimento em 1978, com o Movimento Negro Unificado Contra a Discriminação Racial (MNU), o lançamento do primeiro volume da série Cadernos Negros e a fundação, em 1980, do coletivo cultural Quilombhoje. Nessa medida, a última parte do trabalho - talvez a mais densa no que tange aos materiais analisados e às propostas teórico-metodológicas - dedicase à articulação entre obras, autores e ideias nesse período. Trata-se de um momento importante do diagnóstico, em que o autor percorre uma 
variedade de metodologias e lança mão de um sem-fim de instrumentais analíticos, perseguindo as exigências do objeto em questão e do recorte empírico e temporal analisado. Com isso, tenta verificar conexões, recorrências e obstáculos de problemas levantados, tanto por escritores negros quanto pelos periféricos. Condições sociais de produção, análise de trajetórias, história social de grupos marginalizados, alianças políticas e ações coletivas entre sujeitos e movimentos, embate entre diversidade e desigualdade, circunstância marginal da história e da produção da literatura negra e periférica dentro do sistema literário são só alguns vieses adotados pelo sociólogo.

No decorrer de cinco capítulos, dilemas centrais da relação dialética entre escritor e movimento são enfrentados. Talvez o maior exemplo oferecido pelo pesquisador seja o de Carolina Maria de Jesus, que, na década de 1960, favelada e catadora de papel, sai do anonimato graças à influência do jornalista Audálio Dantas, que possibilitou a publicação de seu diário, sob o título sugestivo de Quarto de despejo (2005 [1960]). Mário Augusto coloca em evidência a relação da escritora com seus coetâneos, que se viam engajados, de um lado, na consolidação de uma estética literária negra e, de outro, no ativismo político propriamente dito - como a Associação Cultural do Negro (ACN). Para isso, Mário sugere uma "Sociologia da Lacuna", a fim de verificar o processo pelo qual, eventualmente, certas personalidades trilharam, de modo isolado, caminhos em direção ao protagonismo social, ignorando agendas políticas de seus pares mais engajados e organizados - quedando-se, assim, deslocados, "fora de lugar", em relação aos repertórios de enfrentamento manejados pelos ativistas.

Não se pode negar que há escritores que se atrelam imediatamente às ideias e pautas defendidas por coletivos políticos e culturais, defendendo-as em suas criações estéticas. No entanto, apesar de negros e/ou periféricos, muitos outros escritores as repelem ou as ignoram. Então, por que as ideias de literatura negra e periférica não vêm à tona e se desenvolvem como proposições estéticas mais ou menos coerentes, tendo de lidar vez e outra com questões sociais nas quais seus grupos de origem estão envolvidos? Lógicas de análise e perguntas norteadoras similares são propostas para os "casos" de Paulo Lins e Ferréz.

Em 1997, Paulo Lins, de origem social semelhante à de Carolina - a quem, contudo, afirma desconhecer e com quem diz não possuir muitas afinidades -, publica Cidade de Deus (2008), um dos grandes romances 
da década, reconstruindo o universo social do conjunto habitacional que dá nome à obra. Mário afirma que o escritor carioca, sem querer ser negro ou periférico, pelo menos literariamente, "tem de lidar com o drama de ser os dois, socialmente"; e, assim o fazendo, foi capaz de compor "um romance impactante sobre diferentes aspectos da desigualdade social no Brasil, com fina criatividade literária que poucos escritores (negros e não negros) jamais tiveram" (p. 592). Em 2000, é a vez do paulistano Ferréz, pseudônimo de Reginaldo Ferreira da Silva, retratar o cotidiano violento das periferias da zona sul de São Paulo em Capão Pecado (2005). ${ }^{2}$ A pergunta subjacente a essa parte da tese é: como foi possível o surgimento de tais escritores em determinadas condições sócio-históricas? Pois, de inicio, tem-se que negros e pobres não produzem literatura, dada sua marginalidade - social, política, econômica, cultural. Mas, quando esses escritores vêm à cena, gera-se espanto. Tal é o universo do insólito onde habitam a literatura negra e a literatura periférica.

O "insólito" que compõe, inclusive, o título da obra, conforme esclarece o autor, opera como um tipo de mão dupla do cotidiano:

Pauta-se, por um lado, pela história e pelas condições sociais em que negros e periféricos majoritariamente se encontram e vivenciam; por outro, pela negação da negação, o princípio de afirmação do eu e do sujeito social que faz com que o ativismo político e a criação literária de autores negros e periféricos se tornem possíveis. Contudo, o insólito se apresenta assim também porque se constroem prejulgamentos sobre os lugares naturais e naturalizados para sujeitos nascidos e socializados em determinadas condições sociais. Quando ocorre a negação da negação, gera-se a pergunta de espanto. O insólito existe, portanto, porque, apesar de tudo, existe a História, e nela se desvelam horizontes de possibilidades, que se confirmam ou não (p. 29).

A negação da negação é, justamente, recusar aquilo que já lhe é negativo, saltando, de forma emancipatória, em direção à positividade. Eis a hipótese de uma obra capaz de surpreender a todos os que se

\footnotetext{
${ }^{2}$ Em 2001, 2002 e 2004, Ferréz foi organizador de três edições do suplemento publicado pela Caros Amigos intitulado Literatura marginal: a cultura da periferia. A primeira edição vendeu mais de 15 mil exemplares, viabilizando o lançamento das outras duas edições, que reuniram um total de 48 escritores e 80 textos sobre a condição periférica, tanto dos escritores quanto de sua produção.
} 
permitirem viajar por mais de quarenta anos de história social da literatura negra e periférica no Brasil.

\section{Referências}

BENJAMIN, Walter (1996). Magia e técnica, arte e política. São Paulo: Brasiliense.

FERNANDES, Florestan (2008 [1964]). A integração do negro na sociedade de classes. 5. ed. São Paulo: Globo.

FERRÉZ (2005). Capão Pecado. Rio de Janeiro: Objetiva.

GAGNEBIN, Jeanne Marie (2006). Lembrar, escrever, esquecer. São Paulo: 34.

JESUS, Maria Carolina (2005 [1960]). Quarto de despejo: diário de uma favelada. 9. ed. São Paulo: Ática

LINS, Paulo (2008). Cidade de Deus. São Paulo: Companhia das Letras.

NASCIMENTO, Érica Peçanha do (2009). Vozes marginais na literatura. Rio de Janeiro: Aeroplano. 